\title{
ANALISIS NATRIUM BENZOAT PADA SAOS DI YOGYAKARTA
}

\author{
Siti Fatimah ${ }^{1}$, Dian Wuri Astuti ${ }^{2}$,Ni Putu Ayu Kurniasih ${ }^{3}$ \\ 1,2,3 D3 Analis Kesehatan STIKes Guna Bangsa Yogyakarta
}

\begin{abstract}
Background: Preservative can block or slow process of fermentation, acidity and analyzes that cause by microbe. Sodium benzoate is one of organic preservative that easy to dissolve and usually additional with various of ingredients like sauce. Sauce is a fluid that can make food tasty. Sauce can be lasting if add by sodium benzoate. Sodium benzoate as preservative can be dangerous for healthy if out maksimum level, and that interested research sodium benzoate. The research purposeto know about sodium benzoate and then determine content level existence on samples of sauce bottle on Beringharjo market in Yogyakarta.
\end{abstract}

Research methods: The research describe sodium benzoate exiztence on saos and than determine sodium benzoate level on saos. The research object sodium benzoate. Statistical variable in this research is one variable that is the existence and level of sodium benzoate on samples. Method that used for analyzed sodium benzoate in this case is base-acid titration in alkalimatri with two test that is kualitatif test and kuantitatif test. This data is set out in table.

Result: The research result by samples is $100 \%$ contain sodium benzoate and preservative with high level or out of maksimum level that has been certained and did not fulfill the terms of regulation BPOM Nomor 36 Tahun 2013 is $41,70 \%$.

Conclusion: there is sodium benzoate preservative on samples of sauce bottle on Beringharjo market in Yogyakarta with level maximum $7.001,61 \mathrm{mg} / \mathrm{kg}$ and level minimun $420,175 \mathrm{mg} / \mathrm{kg}$

Keywords: food preservative, sauce, base-acid titration, alkalimetri.

\section{PENDAHULUAN}

Bahan pengawet umumnya digunakan untuk mengawetkan pangan yang mempunyai sifat mudah rusak. Bahan ini dapat menghambat atau memperlambat proses fermentasi, pengasaman, atau penguraian yang disebabkan oleh mikroba.Produsen menggunakannya pada pangan yang relatif awet dengan tujuan untuk memperpanjang masa simpan atau memperbaiki tekstur. Penggunaan pengawet dalam pangan harus tepat, baik jenis dan dosis yang digunakan. Suatu bahan pengawet mungkin efektif untuk mengawetkan pangan tertentu, tetapi tidak efektif untuk mengawetkan pangan lainnya karena pangan mempunyai sifat yang berbeda-beda sehingga mikroba perusak yang akan dihambat pertumbuhannya juga berbeda. Pada saat ini, masih banyak ditemukan penggunaan bahan-bahan pengawet yang dilarang untuk digunakan dalam pangan dan berbahaya bagi kesehatan (Cahyadi, 2012).

Pengawet yang banyak dijual di pasaran dan digunakan untuk mengawetkan berbagai bahan pangan adalah benzoat, yang umumnya terdapat dalam bentuk garamnya yaitu natrium benzoat atau kalium benzoat yang bersifat mudah larut. Benzoat sering digunakan untuk mengawetkan berbagai pangan dan minuman, seperti sari buah, minuman 
ringan, saos tomat, saos sambal, selai, jeli, manisan, kecap dan lain-lain (Cahyadi, 2012). Buah tomat dijadikan salah satu bahan baku untuk pembuatan pasta karena kandungan antioksidan yang terdapat pada buah tomat sangat baik bagi tubuh. Antioksidan yangsering diperoleh dari asupan makanan banyak mengandung vitamin $\mathrm{C}$, vitamin $\mathrm{E}$, betakaroten, senyawa fenolat dan senyawa karotenoid (Nurhayati, 2012). Senyawa-senyawa fenolat total pada buah tomat dapat menangkap radikal bebas, meredam terbentuknya oksigen singlet serta sebagaipendonor elektron. Upaya untuk mempertahankan fenolat total sangat diperlukan dengan menambahkan pengawet terutama untuk produk olahan buah tomat (Siaka, 2009).

Garam benzoat terurai menjadi bentuk efektif yaitu bentuk asam yang tidak terdisosiasi. Bentuk ini mempuyai efektif racun pada pemakaian berlebihan terhadap konsumen, sehingga pemberian bahan pengawet ini tidak boleh melebihi $0,1 \%$ dalam bahan makanan (Winarno, 2004). Apabila tubuh mengkonsumsi bahan pengawet ini secara berlebih, dapat mengganggu kesehatan, terutama menyerang syaraf (Anonim, 2007).

Daftar penggunaan dan dosis maksimum bahan pengawet organik yang diizinkan pemakaiannya oleh Kepala Badan Pengawasan Obat dan Makanan Republik Indonesia (BPOM) Nomor 36 Tahun 2013, terhadap penggunan natrium benzoat pada saos tomat adalah 1.000 $\mathrm{mg} / \mathrm{kg}$. Berdasarkan Penelitian Lembaga Konsumen Jakarta (LKJ) tahun 2013, terdapat $80 \%$ merk saos dan kecap yang dijual di pasaran mengandung bahan pengawet natrium benzoat dan kalium benzoat berlebihan. Uji laboratorium menunjukan kadar natrium benzoat yang digunakan itu mencapai $1.109,4 \mathrm{mg} / \mathrm{kg}$ (Nurhasan, 2013). Berdasarkan penelitian yang dilakukan Siaka tahun 2009 di wilayah kota Denpasar, diperoleh bahwa kadar benzoat pada saos tomat berkisar antara $600,12-1271,86 \mathrm{mg} / \mathrm{kg}$.

\section{METODE PENELITIAN}

Penelitian ini bersifat deskriptif. Obyek pada penelitian ini adalah natrium benzoat. Variabel pada penelitian ini adalah variabel tunggal yaitu ada tidaknya serta kadar natrium benzoat pada sampel yang diteliti. Metode yang digunakan untuk menganalisis natrium benzoat ini menggunakan Titrasi Asam-basa secara Alkalimetri dengan dua uji yaitu Kualitatif dan kuantitatif. Data yang diperoleh disajikan dalam bentuk tabel.

\section{Bahan : saos}

Reagensia : $\mathrm{NaOH} 0,0791 \mathrm{~N}, \mathrm{NaOH}$ $10 \%, \mathrm{HCl}$ pekat, $\mathrm{FeCl}_{3} 5 \%, \mathrm{NH}_{3} 0,1 \mathrm{~N}$, $\mathrm{NaCl}, \mathrm{NaCl}$ jenuh, Aquadest, Chloroform murni, Indikator fenolftalein (pp) $0,1 \mathrm{~N}$, Kalium hidrogen Platalat (KHP)

Peralatan : Neraca analitik, Gelas beker, Pipet volume, Buret, Labu ekstraksi pelarut, Gelas ukur, Pepet tetes, Pemanas listrik, Sendok penyu, Hairdrier

\section{Tahap Pelaksanaan}

1. Pengambilan saos

Pengambilan semua jenis sampel saos yang dikemas dalam bentuk botol dilakukan secara acak di Pasar Beringharjo Yogyakarta.

2. Perlakuan saos

a. Penyiapan saos

Masing-masing sampel saos ditimbang dengan neraca analitik sebanyak $50 \mathrm{gr}$.

b. Pembuatan $\mathrm{HCl}$ (1:3) dalam 100 $\mathrm{ml}$

1). Diambil $75 \mathrm{ml}$ aquadest dengan gelas ukur dan dimasukkan ke dalam gelas kimia.

2). Diambil $25 \mathrm{ml} \mathrm{HCl}$ menggunakan gelas ukur, kemudian dimasukkan ke dalam gelas kimia yang telah diisi akuades melalui dinding.

3). Dicampur hingga homogen.

c. Pembuatan $\mathrm{NaCl}$ jenuh

Dilarutkan $\mathrm{NaCl}$ dalam aquadest hingga $\mathrm{NaCl}$ tidak larut lagi.

Prosedur kerja:

1) Saos yang telah ditimbang tadi ditambahkan $15 \mathrm{gr} \mathrm{NaCl}$ dan $\mathrm{NaOH} 10 \%$ hingga diperoleh larutan yang bersifat alkalis.

2) Kemudian larutan tersebut diencerkan dengan larutan 250 
$\mathrm{ml} \mathrm{NaCl}$ jenuh dan dibiarkan selama 2 jam.

3) Larutan tersebut dikocok setiap 30 menit dan selanjutnya disaring dengan kertas saring. Filtrat yang diperoleh kemudian diekstraksi.

d. Pembuatan Kalium Hidrogen Platalat (KHP)

1) Ditimbang 2,0433 gr KHP.

2) Dilarutkan ke dalam aquadest yang telah dididihkan dan didinginkan sampai $50 \mathrm{ml}$ dalam labu ukur lali dihomogenkan.

e. Pembakuan $\mathrm{NaOH} 0,1 \mathrm{~N}$

1) Diambil $10 \mathrm{ml}$ larutan KHP yang telah dilarutkan dalam labu ukur $100 \mathrm{ml}$ kemudian dimasukkan ke dalam erlenmeyer.

2) Ditambahkan 2 tetes indikator pp.

3) Dititrasi dengan larutan $\mathrm{NaOH}$ hingga terjadi perubahan warna menjadi merah muda tipis.

Perhitungan:

$10 \frac{\operatorname{gr} \mathbb{K H P}}{\operatorname{EEHP}}=\mathrm{ml}$ titrasi $\times \mathrm{N} \mathrm{NaOH}$

3. Ekstrasi sampel

a. Filtrat yang diperoleh pada penyiapan sampel, dipipet $100 \mathrm{~mL}$ dan dimasukkan ke dalam corong pisah.

b. Kemudian dinetralkan dengan penambahan $\mathrm{HCl} \quad(1: 3)$ dan ditambahkan lagi $5 \mathrm{~mL} \mathrm{HCl}$ sesudah keadaan netral tercapai.

c. Selanjutnya diekstraksi dengan pelarut chloroform sebanyak 2 kali dengan volume yang berturut-turut $30 \mathrm{ml}$ dan $30 \mathrm{ml}$ untuk mencegah emulsi, dengan digoyang-goyang secara kontinyu setiap kali ekstraksi dengan gerakan memutar/rotasi.

d. Lapisan chloroform kemudian ditampung dari setiap ektraksi dengan volume pelarut tersebut.

e. Semua lapisan dietil eter setiap ekstraksi dikumpulkan, ekstrak tersebut kemudian diuapkan dengan hairdryer hingga kering. f. Filtrat yang telah kering kemudian dilarutkan dengan $50 \mathrm{ml}$ alkohol.

4. Uji kualitatif

a. Larutan saos hasil ekstraksi tersebut diambil sebanyak $10 \mathrm{ml}$.

b. Ditambahkan larutan $\mathrm{NH}_{3}$ sampai larutan tersebut menjadi basa.

c. Larutan tersebut kemudian diuapkan di atas penangas air. Residu yang diperoleh, dilarutkan dengan air panas dan disaring.

d. Selanjutnya ditambahkan 3-4 tetes $\mathrm{FeCl}_{3} 0,5 \%$. Adanya endapan yang berwarna merah muda menunjukkan adanya asam benzoat.

5. Uji kuantitatif

a. Larutan saos hasil ekstraksi dipipet sebanyak $10 \mathrm{ml}$ dengan pipet volume.

b. Kemudian dimasukan ke dalam labu Erlenmeyer $250 \mathrm{ml}$. Larutan tersebut ditambah 2-3 tetes indikator pp.

c. Selanjutnya dititrasi dengan larutan $\mathrm{NaOH} 0,1 \mathrm{~N}$ yang telah dibakukan.

d. Volume larutan $\mathrm{NaOH} 0,1 \mathrm{~N}$ yang digunakan dicatat. Pengulangan titrasi dilakukan masing-masing 2 kali.

\section{Tahap Akhir}

Menyimpulkan hasil penelitian dan membuat laporan hasil penelitian.

Pengolahan Data dan Analisis Data

Pengolahan data yang dilakukan dalam penelitian ini adalah deskriptif dan disajikan dalam bentuk narasi dan tabel.

\section{HASIL DAN PEMBAHASAN}

Hasil pemeriksaan menunjukkan 12 sampel saos di pasar beringharjo Yogyakarta positif menggunakan pengawet natrium benzoat dengan kadar yang melampaui batas sebanyak 5 sampel yaitu lebih dari $1.000 \mathrm{mg} / \mathrm{kg}$ menurut Peraturan Kepala BPOM Republik Indonesia Nomor 36 Tahun 2013. Proses pemeriksaan saos meliputi persiapan saos, saos ditimbang sebanyak $50 \mathrm{gr}$ kemudian ditambahkan $15 \mathrm{gr}$ serbuk 
$\mathrm{NaCl}$ yang bertujuan memecah emulsi saos karena emulsi dapat dipecah dengan menambahkan elektrolit. Pemecahan emulsi dilakukan dengan tujuan agar sampel tidak tercampur dengan aquadest sehingga saat dilakukan ekstraksi didapatkan filtrat yang murni. Selanjutnya dilakukan penambahan $\mathrm{NaCl}$ jenuh dengan cara melarutkan serbuk $\mathrm{NaCl}$ kedalam aquadesthingga bubuk $\mathrm{NaCl}$ tidak larut lagi dalam aquadesttujuan penambahan $\mathrm{NaCl}$ jenuh ini untuk menambah tingkat ionisasi dari air menjadi lebih polar sehingga tingkat percampuran air dengan chloroform tidak bertambah yang bermanfaat dalam fase pemisahan atau ekstraksi sampel. Pemeriksaan natrium benzoat dilakukan dengan dua uji yaitu uji kualitatif untuk menunjukkan keberadaan benzoat dalam saos dan dilanjutkankeuji kuantitatif untuk mengetahui kadar benzoat yang terkandung dalam sampel saos.

1. Uji kualitatif

Pada uji kualitatif saos yang telah diektrasi diencerkan dengan alkohol netral yang dicek dengan menggunakan kertas $\mathrm{pH}$ dengan tujuan untuk melarutkan filtrat yang telah kering karena penguapan kemudian dipipet sebanyak $10 \mathrm{ml}$ selanjutnya ditambahkan larutan $\mathrm{NH}_{3}$ hingga basa. Larutan tersebut selanjutnya diuapkan di atas penangas air dengan tujuan menghilangkan air yang terkandung dalam larutan kemudian dilarutkan lagi dengan air panas dan disaring yang bertujuan untuk menghilangkan endapan-endapan yang terdapat dalam larutan saos sehingga didapatkan larutan sampel yang murni. Larutan saos siap untuk dilakukan uji kualitatif dengan penambahan $\mathrm{FeCl}_{3} 0,5 \%$

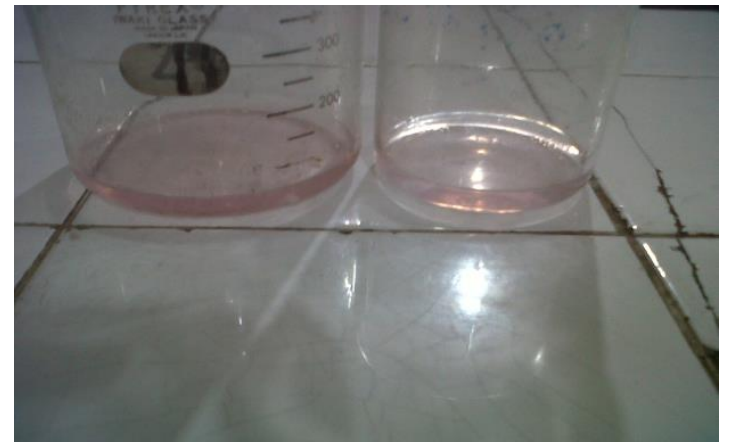

Gambar 4. Pembentukan warna merah muda pada saos yang diperiksa

\begin{abstract}
Terbentuknya warna merah muda pada residu menunjukkan bahwa sampel saos yang diperiksa positif (+) mengandung bahan pengawet organik yaitu natrium benzoat. Warna merah muda terbentuk saat dilakukan penambahan 3-4 tetes $\mathrm{FeCl}_{3}$ 0,5\% pada uji kualitatif, dikarenakan $\mathrm{FeCl}_{3}$ bereaksi dengan benzoat yang terkandung dalam sampel membentuk Besi(III)bezoat $\left[\mathrm{Fe}\left(\mathrm{C}_{6} \mathrm{H}_{5} \mathrm{COOH}\right)_{3}\right]$ atau feri benzoat dengan reaksi:
\end{abstract}

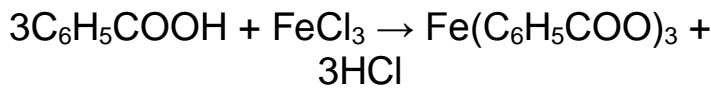

2.Uji kuantitatif

Pada uji kuantitatif menggunakan metode Titrasi Asam-Basa secara Alkalimetri,dimana prinsip dari pemeriksaan tersebut ialah natrium benzoat dipisahkan dari sampel dengan menjenuhkan sampel terlebih dahulu menggunakan $\mathrm{NaCl}$ kemudian diasamkan dengan $\mathrm{HCl}$ encer dan diekstraksi dengan chloroform. Lapisan chloroform diuapkan hingga bebas asam. Residu(hasil saos yang telah diekstraksi) dilarutkan dengan alkohol netral, kadar natrium benzoat ditetapkan dengan cara titrasi menggunakan larutan standar $\mathrm{NaOH}$.Hasil dari pemeriksaan ditunjukkan dengan terbentuknya warna merah muda pada residu yang dititrasi, reaksi yang terjadi yaitu:

$$
\mathrm{C}_{6} \mathrm{H}_{5} \mathrm{COOH}+\mathrm{NaOH} \rightarrow \underset{\mathrm{H}_{2} \mathrm{O}}{\mathrm{C}_{6} \mathrm{H}_{5} \mathrm{COONa}+}
$$

Sebelum dilakukan uji kuantitatif $\mathrm{NaOH}$ dibakukan terlebih dahulu dengan 
tujuan untuk mendapatkan kestabilan normalitas $\mathrm{NaOH}$ yang digunakan karena $\mathrm{NaOH}$ merupakan larutan standar sekunder tidak tersedia dalam keaadaan murni. Pembakuan $\mathrm{NaOH}$ dilakukan menggunakan larutan standar primer yang tersedia dalam komposisi kimia yang jelas dan murni yaitu Kalium Hidrogen Platalat (KHP), sehingga larutan tersebut hanya bereaksi pada kondisi titrasi dan tidak melakukan reaksi sampingan dengan membentuk reaksi sebagai berikut:

$\mathrm{KH}\left(\mathrm{C}_{8} \mathrm{H}_{4} \mathrm{O}_{4}\right)+\mathrm{NaOH} \rightarrow \mathrm{KNa}\left(\mathrm{C}_{8} \mathrm{H}_{4} \mathrm{O}_{4}\right)+$
$\mathrm{H}_{2} \mathrm{O}$

Uji kuantitatif dilakukan dengan cara mentitrasi saos menggunakan $\mathrm{NaOH}$ $0,0791 \mathrm{~N}$, dimana residu hasil ekstrasi yang telah diuapkan dilarutkan dengan akohol netral sehingga suasana saos netral selanjutnya dilakukan penambahan indikator pp terlebih dahulu. Penambahan pp sebagai indikator dilakukan karena pp memiliki kandungan warna merah yang akan bereaksi dalam suasana $\mathrm{pH}$ basa, sehingga saat direaksikan dengan $\mathrm{NaOH}$ akan terbentuk warna merah muda. Terbentuknya warna merah muda tipis menunjukkan titrasi dihentikan dan $\mathrm{ml}$ titrasi dicatat untuk dimasukkan ke dalam rumus perhitungan kadar natrium benzoat. Hal ini terlihat dari gambar 6 pada lampiran 4.

Penelitian yang dilakukan oleh siaka tahun 2009 pada saos tomat yang beredar di Wilayah Denpasar didapatkan 33\% sampel saos tomat yang mengandung benzoat melebihi batas maksimum yang diperbolehkan. Pada penelitian yang dilakukan peneliti dengan judul Analisis Natrium Benzoat Pada Saos Di pasar Beringharjo Kota Yogyakarta didapatkan $41,70 \%$ sampel saos yang diperiksa mengandung natrium benzoat yang melebihi batas maksimum yang diperbolehkan.Hal ini menunjukkan produsen masih menambahkan pengawet benzoat dengan kadar yang melampaui batas maksimum diperbolehkan pada saos yang diproduksi. Ada beberapa kemungkinan yang mendasari hal seperti di atas terjadi yaitu:
1. Kurangnya kesadaran produsen mengenai komposisi penggunaan pengawet natrium benzoat.

2. Ketidaktahuan produsen terhadap efek dari penggunaan natrium benzoat yang berlebih terhadap orang yang mengkonsumsinya.

3. Adanya keinginan produsen agar produknya awet dalam kurun waktu cukup lama sehingga penambahan bahan pengawet tidak memperhatikan ketentuan yang berlaku.

Natrium benzoat yang berlebihan akan menumpuk dalam lambung dan akan mengiritasi lambung, pada penderita asma dan orang yang menderita urticaria sangat sensitif terhadap natrium benzoat (Cahyadi, 2012). Urticaria yaitu suatu reaksi yang timbul mendadak (akut), bentol berwarna merah, memutih bila ditekan dan disertai rasa gatal karena pengeluaran histamin yang mengakibatkan pelebaran pembuluh darah dan perembesan cairan dari pmbuluh darah. Metabolisme natrium benzoat dalam tubuh melalui dua tahap reaksi, pertama dikatalisis oleh enzim syntetase dan pada reaksi kedua dikatalisis oleh enzim acytransferase dalam bentuk asam hipurat dalam hati kemudian diekskresikan melalui urin. Sisa natrium benzoat yang yang tidak di ekskresikan sebagai asam hipurat dihilangkan toksisitasnya dan berkonjugasi dengan asam glukoronat dan diekskresikan melalui urin sehingga tidak terjadi penumpukan natrium benzoat dalam tubuh jika dikonsumsi dalam batas kadar maksimum (Anonim, 2007).

\section{KESIMPULAN}

1. Terdapat kandungan natrium benzoat pada 12 sampel saos yang diperiksa di pasar Beringharjo Yogyakarta

2. Prosentase saos yang memenuhi syarat batas penggunaan natrium benzoat menurut Peraturan Kepala Badan Pengawasan Obat dan Makanan Republik Indonesia Nomor 36 Tahun 2013 adalah 58,30\%

3. Kadar natrium benzoat yang terkandung dalam saos di pasar Beringharjo Yogyakarta, yang 
tertinggi adalah $7.001,61 \mathrm{mg} / \mathrm{kg}$ dan yang terendah adalah $205,03 \mathrm{mg} / \mathrm{kg}$.

\section{DAFTAR PUSTAKA}

Adnan, M, 2005, Teknik Kromatografi untuk Analisis Bahan Pangan, Penerbit Andi, Yogyakarta, Halaman 163.

Anonim, 2007,http : //Www. 1911 encylopedia. org/B/BE/BENZOI $A C I D$. Htm, diambil pada tanggal 07 Februari 2014, Yogyakarta.

Cahyadi, W, 2012,Analisis dan Aspek Kesehatan Bahan Tambahan Makanan, Bumi Aksara, Jakarta, Halaman 5, 7-11, 20, 22-23, 29, 36, 56.

Ditjen Pengawas Obat dan Pangan Departemen Kesehatan R, I, 2013, Peraturan Kepala Badan Pengawas Obat dan Makanan Republik Indonesia Nomor 36 Tahun 2013 tentang batas maksimum penggunaan bahan tambahan pangan pengawet.

Khopkar, 2010, Konsep Dasar Kimia Analitik,Universitas Indonesia (UIPress), Jakarta, Halaman 39, 177.

Nurhayati, Kusoro, S, Harjono, 2012,Konsentrasi Natrium Benzoat dan Lama Penyimpanan pada Kadar Fenolat Total Pasta Tomat,Indonesian Journal Chemical Science, Universitas Negeri Semarang, Vol. 1 No. 2, Halaman 159, 161.

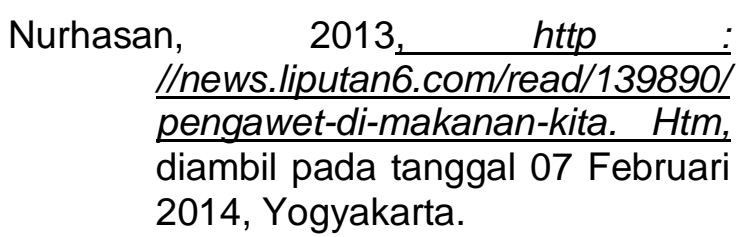

Sardjono,K., Sriwoelan, S., dan Kurnia, F., 2001, Analisis Bahan Tambahan
Pada Makanan, Agritech, Yogyakarta, Halaman 29.

Siaka, 2009, Analisis Bahan Pengawet Benzoat Pada Saos Tomat yang Beredar di Wilayah Kota Denpasar, Skripsi, Jurusan Kimia FMIPA Universitas Udayana, Bukit Jimbaran, Halaman 73, 88, 90.

Sudarmadji, S., Haryono, B., Suhardi, Analisis Bahan Makanan dan Pertanian, Liberty, Yogyakarta, Halaman 162.

Surjowowahyu, 2010, http ://surjowowahyu.files.wordpress.c om/2010/05/sodium-

benzoat,jpg,diambil pada tanggal 07 Februari 2014, Yogyakarta.

Sumarauw, W., Fatimawali., dan Adithya, Y., 2013, Identifikasi Dan Penetapan Kadar Asam Benzoat Pada Kecap Asin Yang Beredar Di Kota Manado, Jurnal IImiah Farmasi, UNSRAT, Vol. 2 No.01, Halaman 13, 15.

Tranggono, 2000, Bahan Tambahan Makanan, Pusat Antar Universitas-Pangan Gizi, Universitas Gajah Mada, Yogyakarta, Halaman 25.

Tranggono dan Sudarmadji, 2001, Buku dan Monograf Bahan Tambahan Makanan (Food Additives), Pusat Antar Universitas-Pangan Gizi, Universitas Gajah Mada, Yogyakarta, Halaman 56.

Wilga,

2001 , http://www.indonesia.com/intisari/ 2001/feb/makanan\%20kemasan. htm, diambil pada tanggal 07 Februari 2014, Yogyakarta.

Winarno, F. G, 2004, Kimia Pangan dan Gizi, Gramedia, Jakarta, halaman 198, 224, 226. 